\title{
Isolation and Identification of Phenolic Acids from Tobacco Leaf*
}

\author{
by M. E. Snook, P. J. Fortson and O. T. Chortyk \\ Tobacco and Health Laboratory, Science and Education Administration / Agricultural Research, \\ United States Department of Agriculture, Athens, Georgia, U.S.A.
}

\section{INT'RODUCTION}

Phenolic acids have been found in tobacco leaf and smoke (1-4). Except for the work of $Y$ ang and Wender (5), who used paper chromatography to separate some of these acids, little work appears to have been done on the isolation and identification of individual phenolic acids of leaf. Our interest in leaf phenolic acids arises from their possible role as precursors of the tumorigenic catechols and phenols of tobacco smoke. Also, the phenolic acids of smoke appear to be concentrated in a weak acid fraction of smoke condensate, and may contribute to this fraction's known biological activity (6). We have developed a relatively simple gel chromatographic method for isolating the phenolic acids from tobacco leaf. This purification method has allowed a more complete identification of these important leaf compounds.

\section{EXPERIMENTAL}

\section{Extraction of Tobacco Leaf}

NC 2326 flue-cured tobacco was ground to pass a 32 mesh screen. The ground tobacco ( $200 \mathrm{~g}$ dry weight) was extracted with 2.5 liters of $1.0 \mathrm{~N} \mathrm{NaOH}$ for 5 min in a Waring Blendor**. The resulting mixture was filtered through \#2 Whatman filter paper by vacuum and the residue was washed with $500 \mathrm{ml}$ of $\mathrm{H}_{2} \mathrm{O}$. The total filtrate was filtered a second time and then extracted with $600 \mathrm{ml}$ of ethyl acetate (EtOAc) to remove non-acidic substances. The filtrate was then acidified to $\mathrm{pH} 1.0(6 \mathrm{~N} \mathrm{HCl})$, satu-

\footnotetext{
- Presented at the 33rd Tobacto Chemisto' Researd Conference beld in Lexington, Kentudy, U.S.A., in 1979.

Received: 10th June 1980 - accepted: 24th Seprember 1980.

** Reference to a company or produce name doas not imply approval or recommendation by the United States Department of Ageiculture.
}

rated with $\mathrm{NaCl}$, and extracted with EtOAc $(3 \times 600 \mathrm{ml})$. The EtOAc solution was dried over anhydrous $\mathrm{MgSO}_{4}$, filtered, and evaporated to yield $6.9 \mathrm{~g}$ of a leaf acid extract, representing a $3.4 \%$ yield. The acids extract was dissolved in $25 \mathrm{ml}$ of methanol (MeOH)/dhloroform $\left(\mathrm{CHCl}_{\mathrm{g}}\right)[1: 1(\mathrm{v} / \mathrm{v})]$ in preparation for gel dromatography.

\section{Gel Chromatography}

The gel column was a $1.25 \mathrm{~cm}$ inside diameter $\times 55 \mathrm{~cm}$ LC-type column (Laboratory Data Control, Riviera Beach, Florida) packed with Sephadex $\mathrm{LH}-2 \mathrm{O}$ in $\mathrm{CHCl}_{3}$. Solvent flow was $2 \mathrm{ml} / \mathrm{min}$ and $5 \mathrm{ml}$ gel fractions (GF) were collected. One $\mathrm{ml}$ aliquots of the acids extract were introduced onto the column with a loop injection valve. To determine the elution characteristics of standard compounds, we used the following solvent system: $\mathrm{CHCl}_{3}$ up to GF-39, solvent then programmed from $\mathrm{CHCl}_{3}$ to $10 \%$ $\mathrm{MeOH} / \mathrm{CHCl}_{3}$ from $\mathrm{GF}-40$ to 55 , and subsequently held at $10 \% \mathrm{MeOH} / \mathrm{CHCl}_{3}$. For the tobacco acids extract separation, the end of the solvent program was modified to hasten the elution of the dihydroxy aromatic acids and $10 \% \mathrm{MeOH} / \mathrm{CHCl}_{3}$ was increased to $40 \% \mathrm{MeOH} /$ $\mathrm{CHCl}_{3}$ from GF-100 to 115 and then kept at $40 \%$ $\mathrm{MeOH} / \mathrm{CHCl}_{3}$. Eluted materials were monitored at $280 \mathrm{~nm}$ and the gel fractions were pooled into Fractions $A, B, C, D$, and E (Fig. 3).

\section{Gas Chromatography (GC)}

Individual fractions $A$ to $E$ were concentrated on a rotary evaporator under reduced pressure to a small volume (about $250 \mu$ ). Aliquots of these concentrates were placed in microreaction vials, fitted with Teflon-lined caps, with equal volumes of $\mathrm{N}, \mathrm{O}$-bis(trimethylsilyl)trifluoroacetamide (BSTFA). The mixtures were heated at $76^{\circ} \mathrm{C}$ for 15 
min and analyzed with a Hewlett-Packard 5830 gas chromatograph equipped with a $183 \mathrm{~cm} \times 2 \mathrm{~mm}$ inside diameter glass column packed with $6 \%$ OV-17 on 100/120 mesh Chromosorb G-HP (temperature program: $90-250^{\circ} \mathrm{C}$ at $2 \% \mathrm{~min}$; He flow, $20 \mathrm{ml} / \mathrm{min}$; injector, $290^{\circ} \mathrm{C}$; flame detector, $300^{\circ} \mathrm{C}$ ). Compounds were identified by comparison of $\mathrm{GC}$ retention times to those of the standards, by co-injection and by $\mathrm{GC}$-mass spectrometry (MS) data. GC-MS data of GC-separated trimethylsilyl (TMS) derivatives were obtained on a 5930 HewlettPackard mass spectrometer, interfaced to a gas chromatograph equipped with an identical OV-17 column. Capillary GC separations were performed on a $0.25 \mathrm{~mm} \times 38 \mathrm{~m}$ SE-54 wall-coated, open-tubular glass capillary column, operated in the split mode $(50: 1)$. GC conditions were: helium flow with linear velocity of $25 \mathrm{~cm} / \mathrm{s}$; temperature program, $50-200^{\circ} \mathrm{C}$ at $2 \% \mathrm{~min}$; injector, $250^{\circ} \mathrm{C}$; detector, $300^{\circ} \mathrm{C}$.

\section{Synthesis of Dibydroxycinnamaldebydes}

The four isomeric dihydroxycinnamaldehydes $(2,3-, 2,4-$, 2,5-, and 3,4-) were synthesized from formylmethyltriphenylphosphorane (prepared from chloroacetaldehyde and triphenylphosphine according to Trippett and Walker (7)) and the corresponding dihydroxybenzaldehyde in tetrahydrofuran (8). Aliquots of each reaction mixture were treated with equal volumes of BSTFA, heated for $15 \mathrm{~min}$ at $76^{\circ} \mathrm{C}$, and analyzed by GC and GC-MS as above.

\section{${ }^{14} \mathrm{C}$-Recovery Studies}

${ }^{14} \mathrm{C}-\mathrm{Salicy}$ lic acid (ICN Pharmaceuticals, Inc., Irvine, California) and ${ }^{14} \mathrm{C}$-p-hydroxybenzoic acid (California Bionuclear Corp., Sun Valley, California) were purified by silicic acid column chromatography ( $100 \mathrm{~g}$ column of Mallindkrodt, 100 mesh silicic acid). The columns were eluted successively with 1 liter each of $4 \%$ ether (E) / petroleum ether (PE), 10\% E/ PE, and 50\% E/PE. The solvents from the $50 \% \mathrm{E} / \mathrm{PE}$ fractions were evaporated and the purified phenolic acids were redissolved in 1 liter of $\mathrm{MeOH}$. Aliquots of the purified labeled acids were diluted 1:1 with $\mathrm{CHCl}_{3}$ and dromatographed on the gel column as before. Recovery of ${ }^{14} \mathrm{C}$ acids was measured by standard liquid scintillation counting techniques. Aliquots (5 ml, 100,000 d.p.m.*) of each standard were added to additional acids extracts of tobacco leaf, the extracts were acidified and extracted with EtOAc, and the fractions were counted.

\section{RESULTS AND DISCUSSION}

It is known that Sephadex LH-20 gel, with chloroform as solvent, will separate organic compounds on the basis of hydrogen bonding effects. Phenolic materials are strongly adsorbed by the gel and require the addition of methanol to be eluted in a reasonable time. In contrast, hydro-
Figure 1. Gel chromatographic elution curves $(280 \mathrm{~nm})$ of standard phenollc aclds from Sephadex LH-20 (chloroform initially, then programmed to $10 \%$ methanol / chloroform from GF- 40 to 55 , and then maintained at $10 \%$ $\mathrm{MeOH} / \mathrm{CHCl}_{3}$ ).

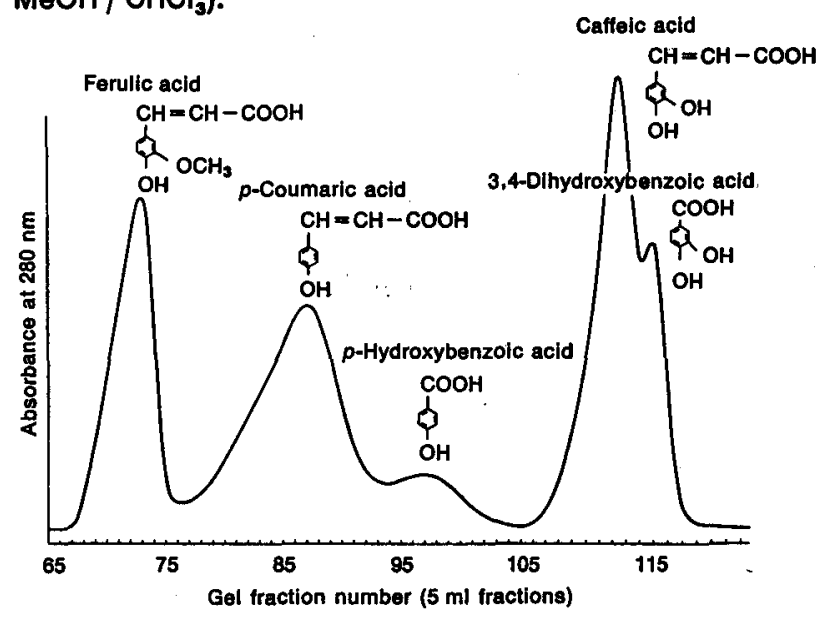

carbons, ketones, aldehydes, alcohols, and amines are not retained and are eluted with the void volume of the column or shortly thereafter. This property of LH-20 is ideally suited to the separation of phenolic constituents from complex mixtures of organic compounds, such as plant extracts.

The elution curves of several phenolic acid standards, among numerous phenolic acids that we have studied with the Sephadex $\mathrm{LH}-2 \mathrm{O}-\mathrm{MeOH} / \mathrm{CHCl}_{3}$ system, are shown in Fig. 1. Acids with internal hydrogen bonding (such as ferulic and salicylic acids) eluted earlier than $p$-coumaric and $p$-hydroxybenzoic acids. Dihydroxybenzoic acids eluted much later. Interestingly, cinnamic acids eluted earlier than the benzoic acids (caffeic before dihydroxybenzoic acid). Other phenolic or acidic compounds, containing two or more hydroxyl groups, were also found to elute in the same gel fractions as the phenolic acids. These included dihydroxybenzaldehydes and di- and tricarboxylic aliphatic acids. We successfully applied these properties of LH-20 to isolate the phenolic acids from a tobacco leaf extract.

Figure 2. Isolation scheme for phenolic acids of tobacco

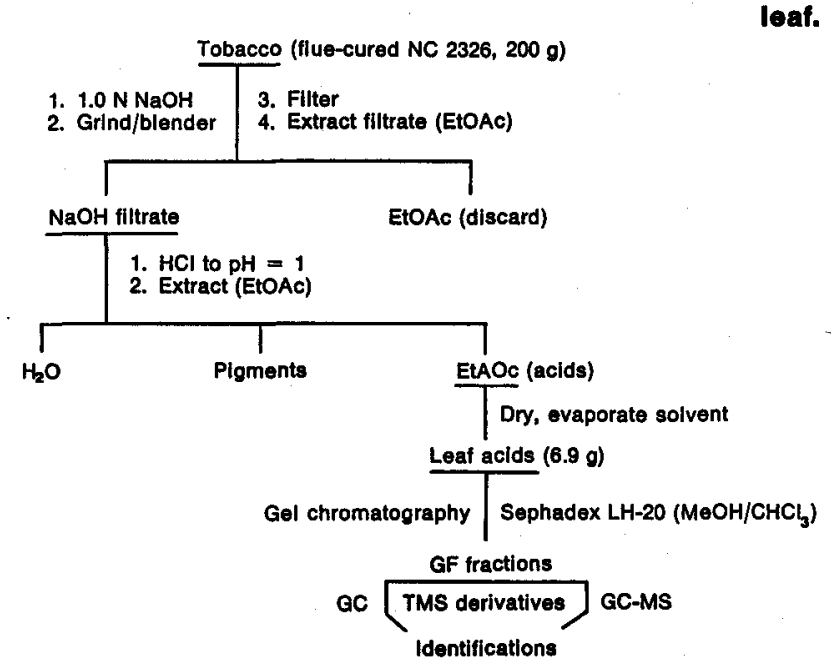


Figure 3. Gel chromatographic elution curve $(280 \mathrm{~nm})$ for the leaf acids extract on Sephadex LH-20 (same solvent program as Flg. 1, except that solvent programmed to $40 \% \mathrm{MeOH} / \mathrm{CHCl}_{3}$ from GF-100 to 115 , and then maintained at that concentration).

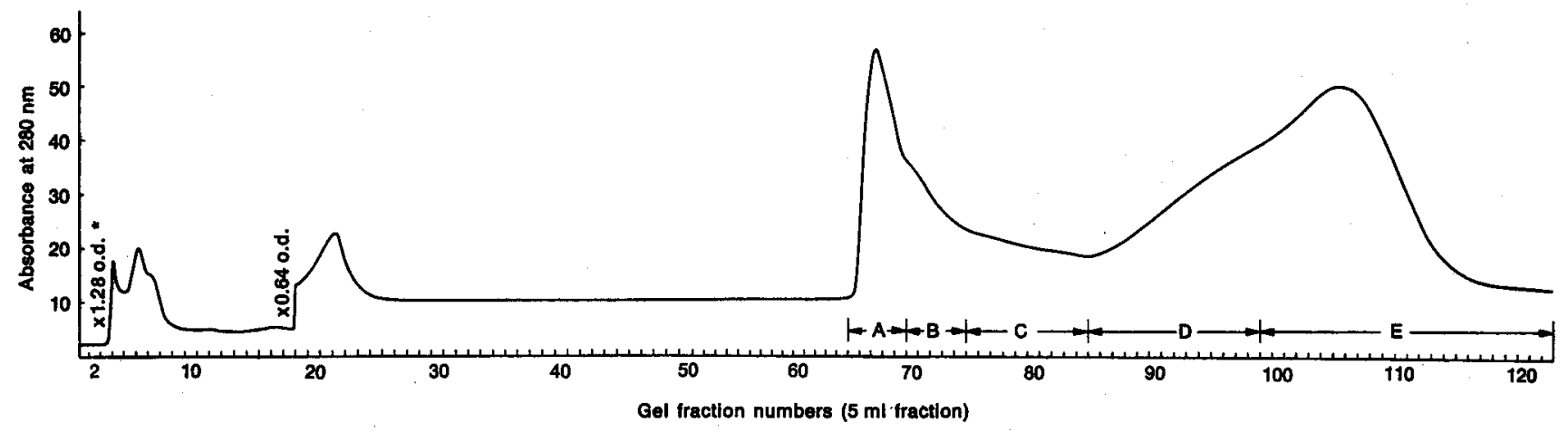

- optical density

Our isolation scheme for the phenolic acids of tobacco leaf is shown in Fig. 2. Briefly, ground, flue-cured, NC 2326 tobacco leaf was treated with aqueous sodium hydroxide to extract free acids or easily hydrolyzed acid derivatives. (Complete extraction of all acid moieties would have required acid and base hydrolyses, under reflux, to cleave possible sugar or ester linkages. However, heating could have destroyed some of the sensitive phenolic compounds.) The sodium hydroxide filtrate, containing the salts of the phenolic acids, was acidified and extracted with ethyl acetate. The extract, representing $3.4 \%$ of leaf weight, was dissolved in $\mathrm{MeOH} / \mathrm{CHCl}_{3}$ $[1: 1(\mathrm{v} / \mathrm{v})]$ and chromatographed on the Sephadex LH-20 gel column. Elution with chloroform and $\mathrm{MeOH} / \mathrm{CHCl}_{\text {s }}$ gave the resulting elution curve $(280 \mathrm{~nm})$ shown in Fig. 3. The elution of the phenolic acids was quite apparent and began in GF-64. Based on the elution curves of standard acids, appropriate gel fractions were combined to give fractions $A, B, C, D$, and $E$.
Fractions $\mathrm{A}$ to $\mathrm{E}$ were then individually analyzed by GC as their volatile TMS derivatives. Identifications were made by GC retention times, co-injections with standards, and by GC-MS data. Mass spectra of TMS - standard acids were compared to those of the isolated compounds. Most of the aromatic acids yielded good TMS molecular ions $\left(M^{+}\right)$and $M^{+}-15$ ions. Aliphatic compounds gave $M^{+}-15$ ions with virtually no molecular ions, unless a double bond was present in the molecule.

Phenolic acids identified in the gas chromatogram of TMS-derivatized fraction A (Fig. 4) included salicylic, vanillic, several isomers of vanillic, cis- and trans-ferulic, caffeic, and cis- und trans-sinapic acids (Table 1). Table 1 gives the percentages of identified compounds within each fraction (A to $E$ ). It is not meant for quantitation of compounds, but is indicative of distribution across the fractions. Several aliphatic compounds were also identified, including $\mathrm{C}_{4}$ - and $\mathrm{C}_{5}$-hydroxy acids and minor amounts of succinic, fumaric, pimelic, and azaleic acids. A trace of

Figure 4. Gas chromatogram of TMS-derlvatized fractlon A (m/e are for TMS derivatives).

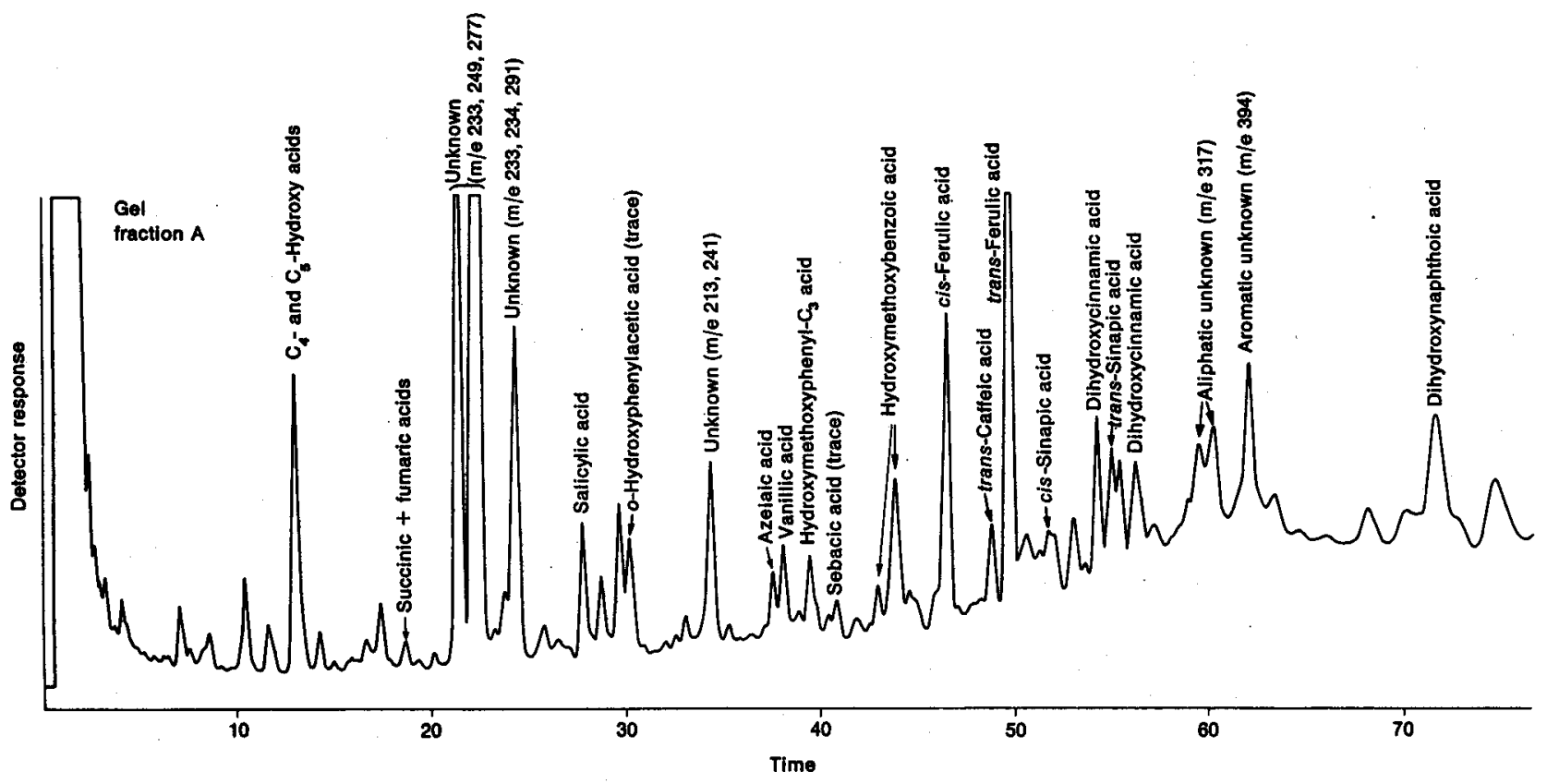


Flgure 5. Gas chromatogram of TMS-derivatized fraction B ( $\mathrm{m} / \mathrm{e}$ are for TMS derivatives).

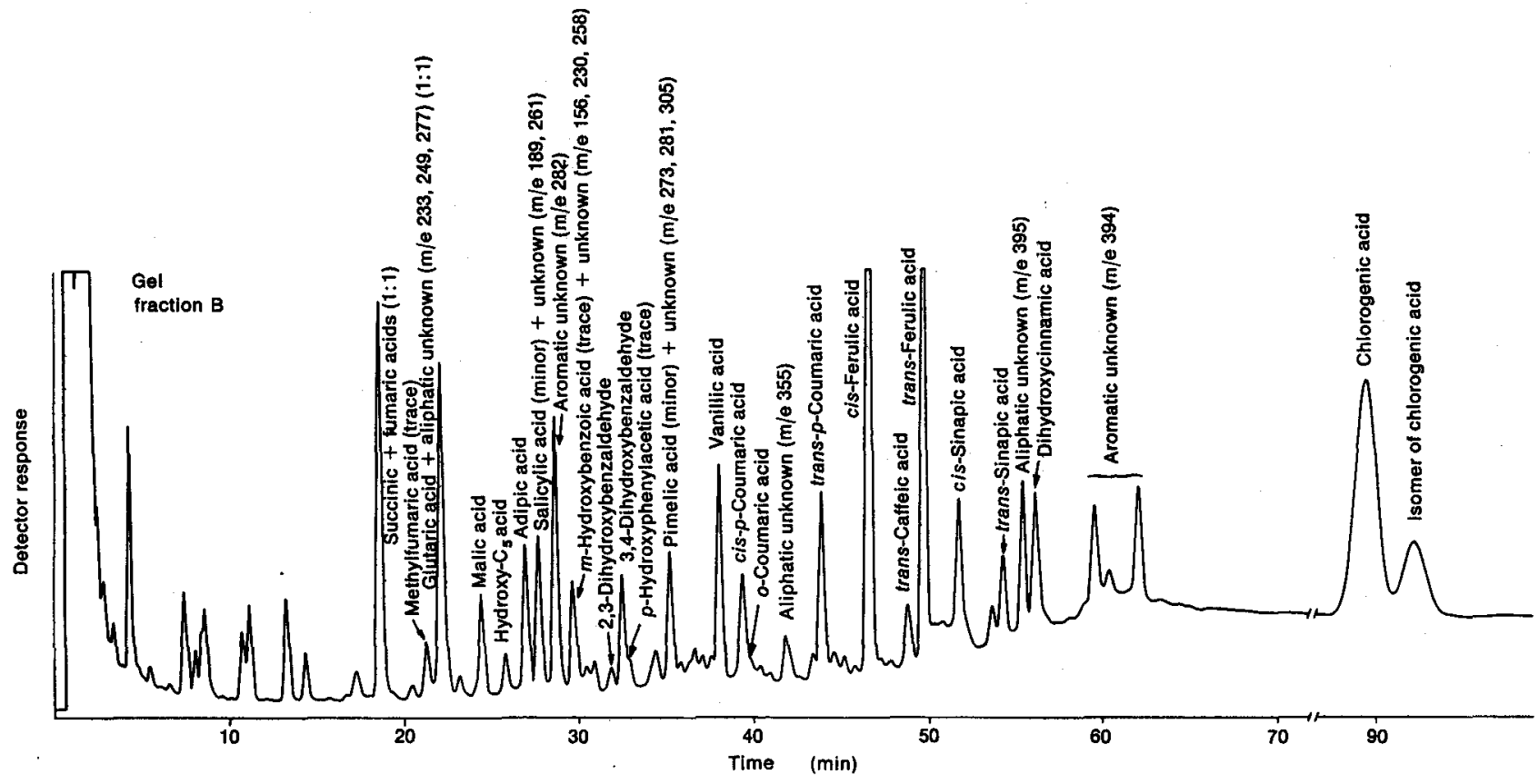

Flgure 6. Gas chromatogram of TMS-derivatized fraction $C(\mathrm{~m} / \mathrm{e}$ are for TMS derivatives).

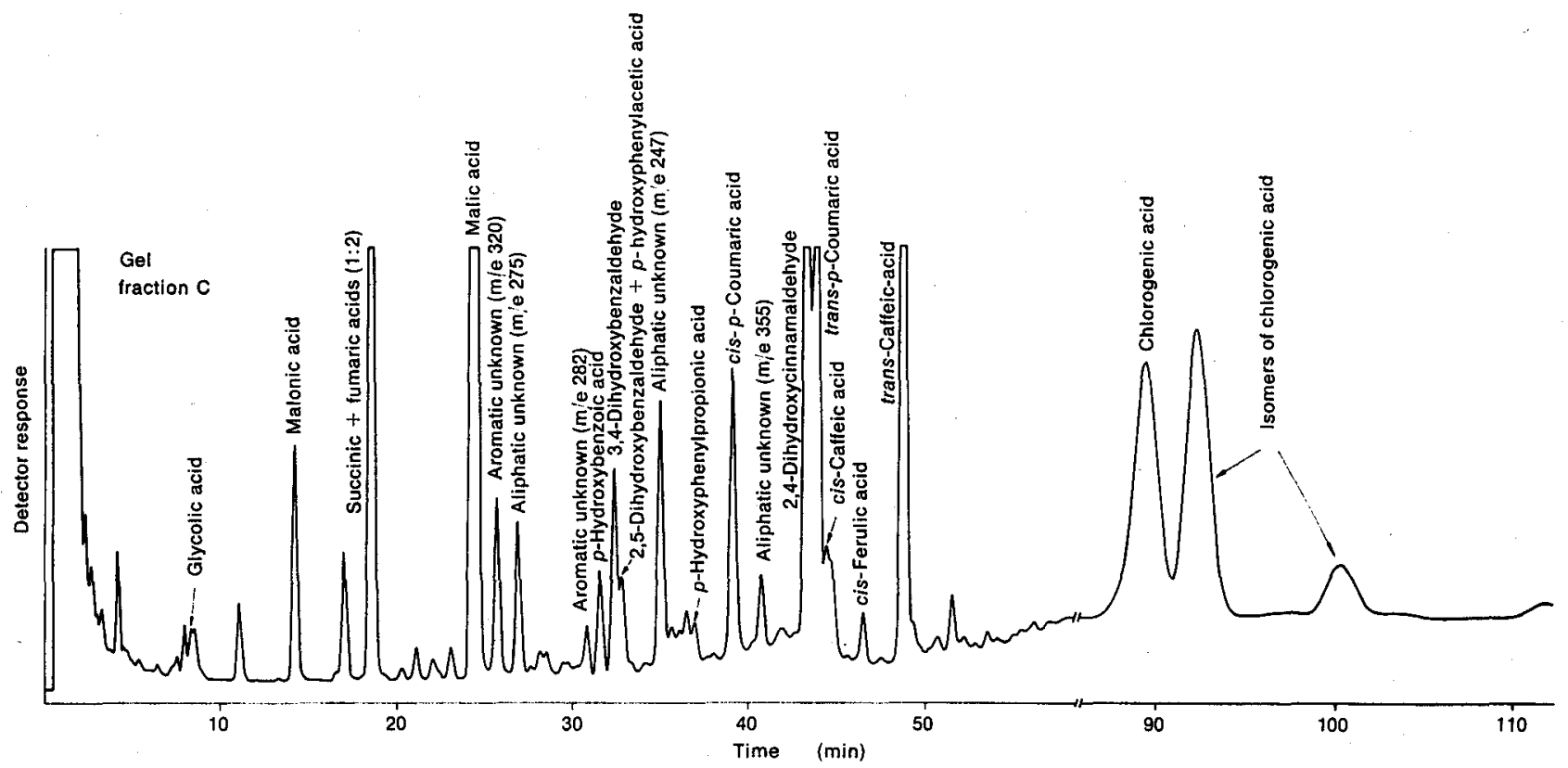


Table 1. Percentage composition of major Identifled compounds in gel fractions.

\begin{tabular}{|c|c|c|c|c|c|}
\hline \multirow{2}{*}{ Acids (aldehydes) } & \multicolumn{5}{|c|}{ Percentage composition } \\
\hline & A & B & $\underbrace{\text { fraction }}_{c}$ & D & E \\
\hline Malonic acid & 0.42 & 0.78 & 2.03 & 0.15 & - \\
\hline Succinic / fumaric acids & 0.20 & 5.76 & 8.46 & 0.39 & - \\
\hline Malic acid & 3.30 & 1.72 & 28.15 & 13.92 & - \\
\hline Salicylic acid & 1.19 & 2.45 & 0.10 & - & - \\
\hline$m$-Hydroxybenzoic acid & - & - & - & 0.05 & - \\
\hline p-Hydroxybenzoic acid & - & 0.79 & 1.02 & 0.50 & - \\
\hline 3,4-Dihydroxybenzaldehyde & 0.09 & 2.38 & 1.92 & - & - \\
\hline Citric / 2,5-dihydroxybenzoic acids & - & - & 0.62 & 1.51 & 2.47 \\
\hline 3,4-Dihydroxybenzoic acid & - & - & - & 0.18 & 1.09 \\
\hline Vanillic acid & 0.86 & 3.72 & 0.43 & - & - \\
\hline trans- $m$-Coumaric acid & - & - & - & 0.18 & - \\
\hline cis-p-Coumaric acid & - & 3.33 & 3.81 & - & - \\
\hline 2,4-Dihydroxycinnamaldehyde & - & 0.76 & 10.12 & - & - \\
\hline trans-p-Coumaric acid & - & 3.22 & 13.09 & 0.28 & - \\
\hline cis-Cafteic acid & - & - & 2.01 & 2.60 & 1.22 \\
\hline c/s-Ferulic acid & 3.23 & 9.61 & 0.46 & - & - \\
\hline trans-Caffeic acid & 1.05 & 1.20 & 9.72 & 77.80 & 91.78 \\
\hline trans-Ferulic acid & 5.51 & 7.71 & - & - & - \\
\hline cis-Sinapic acid & 1.01 & 4.66 & - & - & - \\
\hline trans-Sinapic acid & 1.51 & - & - & - & - \\
\hline Dihydroxynaphthoic acid & - & - & - & 0.49 & 2.61 \\
\hline
\end{tabular}

glutaric acid was also found. Two major peaks in the chromatogram remain unidentified at present. These compounds gave prominent TMS - mass spectral ions at 147, 233,249 , and 277 , indicating TMS derivatives with a molecular weight of 292. An ion of $\mathrm{m} / \mathrm{e} 147$ for a TMS derivative is indicative of two or more TMS groups in a molecule (9). This indicated that the original molecular weight of the unknown compounds was 148 . Possible formulas (assuming minimum requirement of two hydroxyl groups) are $\mathrm{C}_{8} \mathrm{H}_{4} \mathrm{O}_{3}, \mathrm{C}_{7} \mathrm{H}_{18} \mathrm{O}_{3}$ and $\mathrm{C}_{6} \mathrm{H}_{12} \mathrm{O}_{4}$.

Phenolic acids identified in the gas chromatogram of TMS-derivatized fraction B (Fig. 5) included salicylic, $m$-hydroxybenzoic, $p$-hydroxyphenylacetic, vanillic, and $o$-coumaric acids. Also found were cis- and trans-p-coumaric, ferulic, caffeic, and sinapic acids, as well as 2,3and 3,4-dihydroxybenzaldehydes. Identified aliphatic acids were succinic, fumaric, glutaric, malic, adipic, and pimelic acids (Table 1). Two large peaks, found to elute very late in the chromatogram of fraction $B$, were identified as chlorogenic acid and one isomer. Apparently, the dilute base solution used in the leaf extraction did not completely hydrolyze the chlorogenic acid to caffeic and quinic acids.

The gas chromatogram of TMS-derivatized fraction C (Fig. 6) showed that it contained large amounts of succinic, fumaric, malic, cis- and trans-p-coumaric, and caffeic acids (Table 1). $p$-Hydroxybenzoic acid and two dihydroxybenzaldehydes were also found. A compound in the chromatogram of fraction $C$, which immediately preceded the elution of trans-p-coumaric acid, had the same molecular weight as $p$-coumaric acid (TMS derivative $=$ 308), but it was not one of the isomers (ortho or meta) of cis- or trans-coumaric acids. Since we had found dihydroxybenzaldehydes, which are isomeric with hydroxybenzoic acids, we felt that, similarly, a dihydroxycinnamaldehyde was present. Therefore, we synthesized the 2,3-, 2,4-, 2,5-, and 3,4-dihydroxycinnamaldehydes, according to Bravo et al. (8). An aliquot of each reaction mixture was silylated and analyzed directly by GC. Four peaks were observed in each of the chromatograms and when the corresponding compounds were analyzed by GC-MS they proved to be the starting aldehyde, the expected cinnamaldehyde, an unknown compound, and triphenylphosphine oxide. In this manner, we also determined the GC - retention times for the synthesized cinnamaldehydes. On comparison, only the 2,4- and 3,4-dihydroxycinnamaldehydes were found to co-chromatograph with peaks of fraction C. Since 3,4-dihydroxycinnamaldehyde co-eluted with $p$-coumaric acid on our packed columns, wied a 38 meter SE-54 capillary column to cleanly separate all of the synthesized dihydroxycinnamaldehydes from the $p$-coumaric acid. The capillary column separation proved that only the 2,4-dihydroxycinnamaldehyde co-chromatographed with the peak in question. One would have expected the 3,4-isomer to be present in leaf, because several 3,4-dihydroxy compounds such as caffeic acid (3,4-dihydroxycinnamic acid), 3,4dihydroxybenzoic acid, and 3,4-dihydroxybenzaldehyde were found.

The gas chromatogram of TMS-derivatized fraction D 
Flgure 7. Gas chromalogram of TMS-derivatlzed fraction $D$ (m/e are for TMS derivatives).

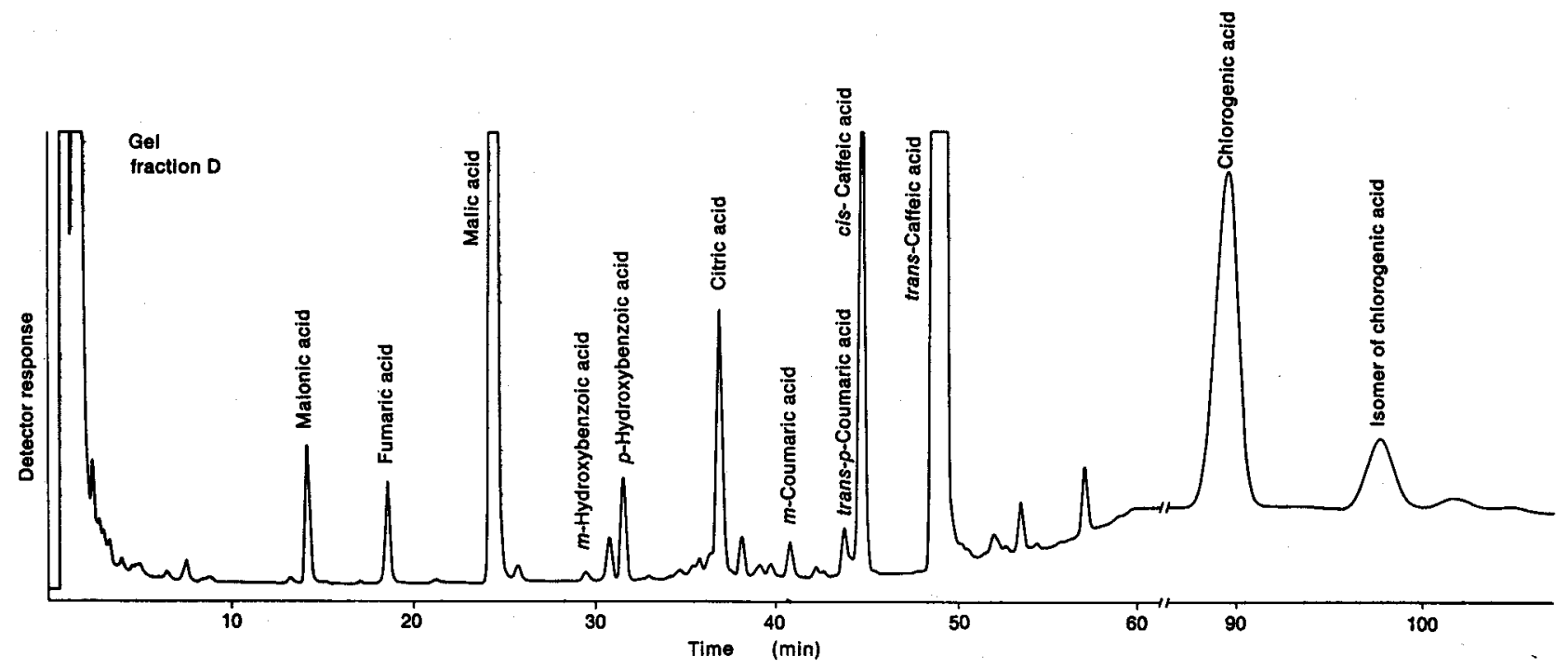

(Fig.7) showed that it was much less complex, but enriched in the compounds most strongly adsorbed by the gel. These included malonic, fumaric, malic, $m$ - and $p$-hydroxybenzoic, citric, $m$-coumaric, trans-p-coumaric, and cis- and trans-caffeic acids (Table 1). The large quantity of caffeic acid is probably due to the partial decomposition of chlorogenic acid. In previous work, we have observed concentrations of chlorogenic acid in tobacco leaf of over $1 \%$. The sodium hydroxide extraction step probably hydrolyzed some of it, as strong base solutions or heat are known to cleave chlorogenic acid to give caffeic acid and quinic acid. No evidence for the presence of quinic acid was found in the EtOAc extract of the total acids, probably due to the greater solubility of quinic acid in the aqueous solution. Chlorogenic acid and an isomer were still present in relatively large concentrations. An examination of the dhromatograms of fractions $A-D$ showed that the cis-isomers of ferulic, $p$-coumaric, sinapic, and caffeic acids eluted from the gels earlier than the trans-isomers.

The gas chromatogram of TMS-derivatized fraction $\mathrm{E}$ is given in Fig. 8. The major component was trans-caffeic acid with minor amounts of citric, 2,5- and 3,4-dihydroxybenzoic, and cis-caffeic acids (Table 1). Upon GC analysis of standard compounds, we found that the six isomeric dihydroxybenzoic acids eluted in three peaks from the OV-17 column. The 2,3-isomer eluted first followed closely by a peak containing the 2,5- and 2,6isomers, which was followed by the co-elution of the 2,4-, 3,4-, and 3,5-isomers in one peak. To determine which

Figure 8. Gas chromatogram of TMS-derlvatized fraction E ( $\mathrm{m} / \theta$ are for TMS derivatives).

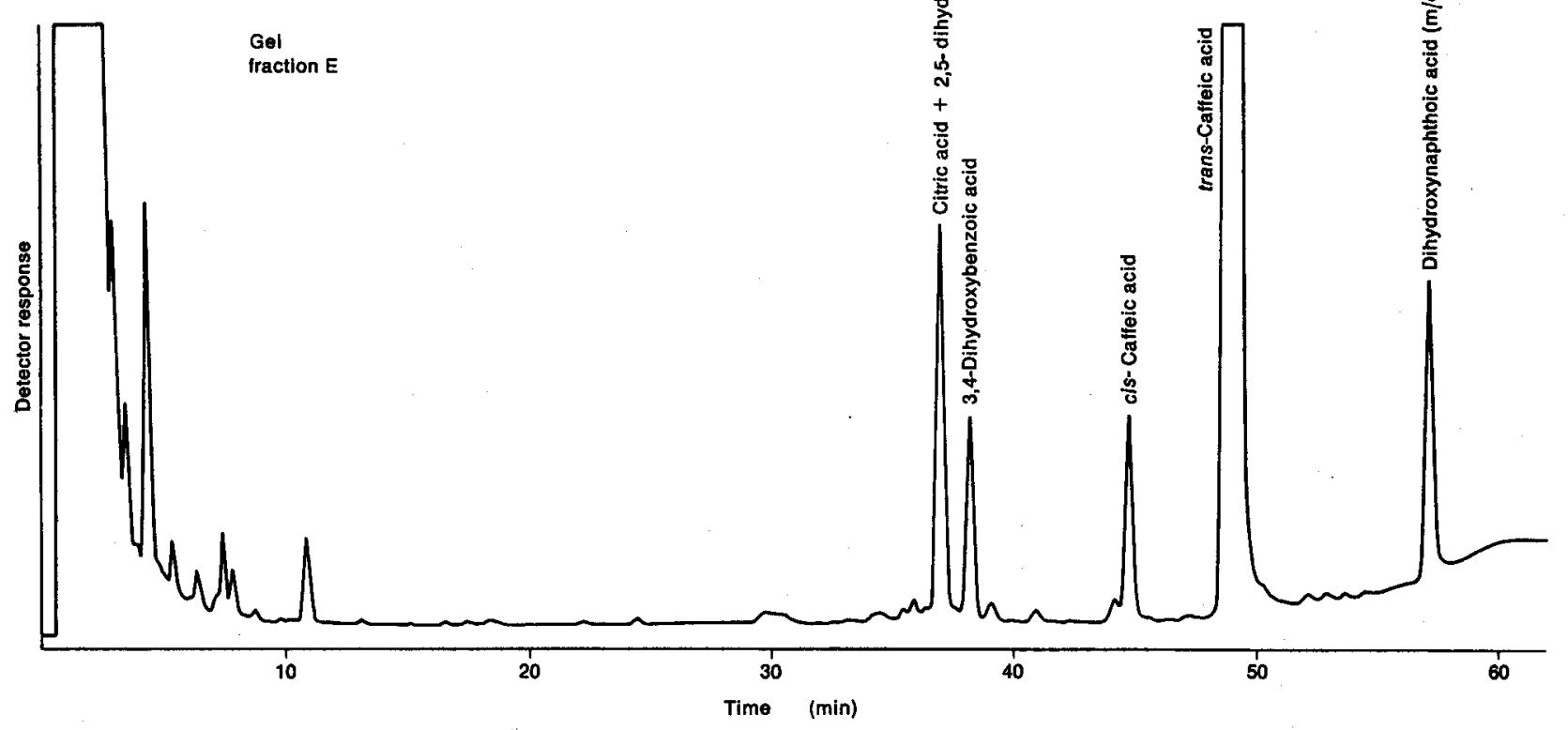


Table 2. Mass spectra of sllylated dlhydroxybenzolc acids.*

\begin{tabular}{l|c|c|c|c|c|c}
\hline \multirow{2}{*}{$\begin{array}{l}\text { m/e of characteristic } \\
\text { fragment lons }\end{array}$} & \multicolumn{5}{|c}{ Relative abundances of fragment lons from the silylated benzoic acids } \\
\cline { 2 - 7 } & $2,3-(\mathrm{OH})_{2}$ & $2,5-(\mathrm{OH})_{2}$ & $2,6-(\mathrm{OH})_{2}$ & $2,4-(\mathrm{OH})_{2}$ & $3,4-(\mathrm{OH})_{2}$ & $3,5-(\mathrm{OH})_{2}$ \\
\hline $370(\mathrm{M})$ & 0.5 & 1.6 & 1.1 & 0 & 22.1 & 88.0 \\
$355(\mathrm{M}-15)$ & 45.5 & 38.6 & 68.0 & 44.0 & 15.0 & 82.7 \\
311 & 0 & 0 & 0 & 0 & 7.1 & 24.0 \\
281 & 0.9 & 2.4 & 0 & 6.1 & 7.1 & 20.0 \\
$269(\mathrm{M}-101)$ & 4.2 & 0 & 27.6 & 0 & 0 & 0 \\
$193(\mathrm{M}-177)$ & 20.8 & 1.3 & 4.3 & 1.9 & 100 & 4.5 \\
147 & 1.7 & 15.8 & 35.4 & 22.7 & 11.4 & 32.0 \\
137 & 19.2 & 0 & 0 & 0 & 7.6 & 2.5 \\
133 & 5.4 & 6.1 & 9.5 & 7.9 & 4.3 & 17.3 \\
73 & 100 & 100 & 100 & 100 & 92.1 & 100 \\
44 & 18.5 & 2.6 & 9.1 & 46.9 & 3.1 & 9.3 \\
\hline
\end{tabular}

- According to H. J. Morita (10).

isomers were present in the leaf extract, we applied GCMS analysis.

Mass spectral data of the TMS derivatives can be used to differentiate between the dihydroxy isomers that co-elute (10). One can determine which of the 2,5- or 2,6-isomers is present by the presence or absence of an ion at $\mathrm{m} / \mathrm{e} 269$ in the mass spectrum (Table 2). The absence of the 269 ion in the mass spectrum of fraction $E$ confirmed that only the 2,5-dihydroxybenzoic acid was present. That is, the GC peak, possibly containing the 2,5- and the 2,6isomers, did not have a 269 ion, indicative of the 2,6isomer. Mass spectrometry also confirmed that only the 3,4-isomer was present in the peak where the 2,4-, 3,4-, and 3,5-isomers co-elute. This was shown by the presence of an ion at $\mathrm{m} / \mathrm{e} 193$, which was also the base peak of the spectrum. The other isomers have virtually no 193 ion in their mass spectra. The 193 ion represents a cyclic rearrangement ion containing a silyl group bridged by oxygens on ortho positions of an aromatic ring. Horvat (11) has shown that the ion appears to be universally formed whenever adjacent hydroxyl groups exist on an aromatic nucleus. He has demonstrated the cyclic ion in mass spectra of dihydroxybenzaldehydes, caffeic acid, gallic acid, and even catechol.

The last peak in the chromatogram of fraction $E$ was identified as dihydroxynaphthoic acid, on the basis of the

Flgure 9. Partial mass spectra of trimethylsllylated 3,4dihydroxybenzolc acld and dihydroxynaphtholc acid.

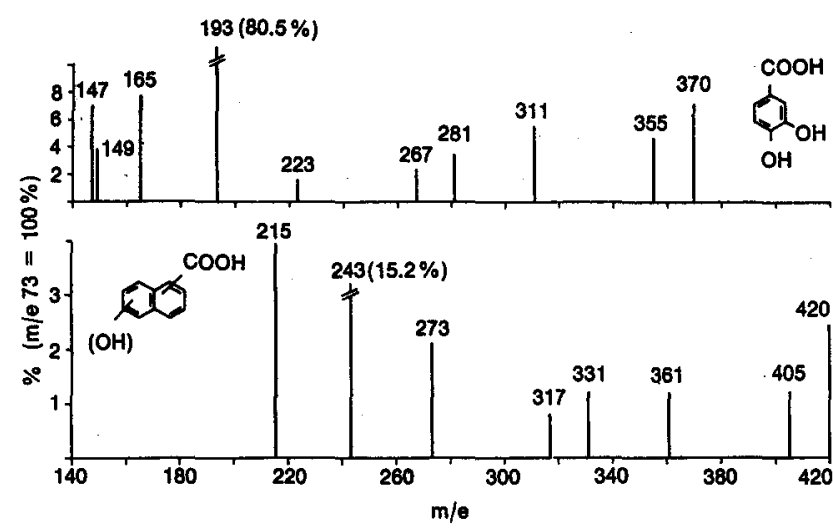

following evidence. The partial mass spectrum of trimethylsilylated 3,4-dihydroxybenzoic acid was compared to the spectrum of the peak labeled "dihydroxynaphthoic acid" (Fig. 9). In the unknown spectrum, the appearance of ions exactly 50 mass units higher than corresponding ions of the dihydroxybenzoic acid spectrum indicated strongly that the unknown was a dihydroxynaphthoic acid. Further, the appearance of a large ion at $\mathrm{m} / \mathrm{e} 243$ (corresponding to the 193 ion of 3,4-dihydroxybenzoic acid) strongly suggested that the phenolic hydroxyl groups were adjacent.

The quantitative recovery of phenolic acids in this chromatographic method was determined with ${ }^{14} \mathrm{C}$-salicylic and ${ }^{14} \mathrm{C}$-p-hydroxybenzoic acids. Aliquots of the purified compounds (in methanol) were added to a portion of the aqueous $\mathrm{NaOH}$ leaf acids extract. The extract was treated as in the isolation scheme and the recovery of the ${ }^{14} \mathrm{C}$ acids was determined. In the extraction step for total leaf acids, the recoveries of ${ }^{14} \mathrm{C}$-salicylic acid and ${ }^{14} \mathrm{C}$ - $p$ hydroxybenzoic acid were 93.1 and $95 \%$, respectively. For the gel chromatographic step, we could not determine the recovery of the ${ }^{14} \mathrm{C}$-labeled acids in the presence of the extract material, due to interference from fluorescent compounds. However, ${ }^{14} \mathrm{C}$-salicylic and ${ }^{14} \mathrm{C}$-p-hydroxybenzoic acids, when chromatographed on the gel column separately, resulted in 90.0 and $99.3 \%$ recoveries, respectively. Therefore, it appears that the entire procedure is quantitative for these compounds and probably for all of the phenolic acids. This method is now being applied to the characterization of phenolic acids in a weak acid fraction of cigarette smoke condensate, which has been shown to contain other active compounds, such as catechols.

\section{SUMMARY}

A new chromatographic method utilizing the hydrogen bonding properties of Sephadex LH-20 gel in methanol/ chloroform, was developed for the isolation of phenolic acids. This method was applied to the characterization of phenolic acids in flue-cured tobacco. Gel chromatography 
successfully isolated and concentrated the phenolic acids from other acidic substances and allowed identification and quantitation of these compounds by GC and GC-MS, as their trimethylsilyl derivatives. Compounds identified included: cis- and trans-isomers of $p$-coumaric, ferulic, caffeic, and sinapic acids; $0-, m$-, and $p$-hydroxybenzoic acids; o-hydroxyphenylacetic acid; $2,5-$ and 3,4-dihydroxybenzoic acids; and 2,3-, 2,5- and 3,4-dihydroxybenzaldehydes. Caffeic acid was the major compound, probably arising from the degradation of the chlorogenic acid of leaf. Aliphatic acids having two or more carboxyl groups were also isolated and included the following: malonic, succinic, fumaric, malic, and citric acids. A dihydroxycinnamaldehyde and a dihydroxynaphthoic acid are reported in tobacco leaf for the first time.

\section{ZUSAMMENFASSUNG}

Für die Isolierung von Phenolsäuren wurde auf der Basis der Wasserstoffbrïckenbildungsfähigkeit des Sephadex-LH-20-Gels in Methanol/Chloroform-Lösung eine neue chromatographische Methode entwickelt. Die in "flue-cured"-Tabak enthaltenen Phenolsäuren wurden unter Anwendung dieses Verfahrens identifiziert. Sie wurden durch Gel-Chromatographie erfolgreich von anderen sauren Bestandteilen abgetrennt und konzentriert und mittels GC bzw. GC-MS in Form ihrer Trimethylsilyl-Derivate qualitativ und quantitativ bestimmt. Folgende Verbindungen wurden identifiziert: cis- und trans-Isomere von $p$-Cumarin-, Ferula-, Kaffeeund Sinapinsäure; $o-, m$ - und $p$-Hydroxybenzoesäure; o-Hydroxyphenylessigsäure; 2,5- und 3,4-Dihydroxybenzoesäure; und 2,3-, 2,5- und 3,4-Dihydroxybenzaldehyd. Kaffeesäure, die wahrscheinlich durch den Abbau der Chlorogensäure des Tabakblattes entstanden war, war quantitativ am stärksten vertreten. Es wurden aud folgende aliphatische Säuren mit zwei oder mehr Carboxylgruppen identifiziert: Malon-, Bernstein-, Fumar-, Apfel- und Citronensäure. Zum erstenmal wird hier über die Identifizierung eines Dihydroxyzimtaldehyds und einer Dihydroxynaphthoesäure im Tabakblatt berichtet.

\section{RESUME}

On décrit une nouvelle méthode chromatographique pour l'isolation des acides phénoliques, basée sur l'aptitude du gel Sephadex $\mathrm{LH}-20$ aे former des liaisons hydrogènes dans une solution de méthanol/chloroforme. Cette méthode a permis l'identification des acides phénoliques dans le tabac sflue-cured». Par la dromatographie sur gel, on a réussi à séparer les acides phénoliques d'autres substances acides, à les concentrer, à les identifier et déterminer quantitativement par GC et GC-MS sous forme de leurs dérivés triméthylsilylés. Les composés identifiés sont les isomères cis et trans des acides p-coumarique, férulique, caféique et sinapique; les acides $0-, m$ - et $p$ hydroxybenzoïque; l'acide o-hydroxyphénylacétique; les acides 2,5- et 3,4-dihydroxybenzoĩque; et les aldéhydes 2,3-, 2,5- et 3,4-dihydroxybenzoïque. L'acide caféique, produit probablement par la dégradation de l'acide chlorogénique de la feuille de tabac, apparaît en grande quantité. On a aussi identifié les acides aliphatiques diet tricarboxyliques suivants: malonique, succinique, fumarique, malique et citrique. Pour la première fois, un aldéhyde dihydroxycinnamique et un acide dihydroxynaphtoïque ont été identifiés dans la feuille de tabac.

\section{REFERENCES}

1. Stedman, R. L.: The chemical composition of tobacco and tobacco smoke; Chem. Rev. 68 (1968) 153-207.

2. Herrmann, K.: Die phenolischen Inhaltsstoffe des Tabaks; Dtsch. Apoth.-Ztg. 101 (1961) 1481-1482.

3. Herrmann, K.: Uber die phenolischen Inhaltsstoffe des Tabaks und des Tabakrauches; Beitr. Tabakforsch. 2 (1964) 159-179.

4. Andersen, R. A., and G. Moegling: Quantitative gas dromatographic assay for caffeic acid moieties in tobacco; Anal. Biochem. 27 (1969) 397-408.

5. Yang, C., and S. H. Wender: Free phenolic acids of cigarette smoke and tobacco paper chromatography, Separation and identification; J. Chromatogr. 8 (1972) 82-89.

6. Bock, F. G., A. P. Swain and R. L. Stedman: Composition studies on tobacco, XIIV. Tumor-promoting activity of subfractions of the weak acid fraction of cigarette smoke condensate; J. Natl. Cancer Inst. 47 (1971) 429-436.

7. Trippett; S., and D. M. Walker: The phosphobetaines, Preparation and properties; J. Chem. Soc. 1962, 1266-1272.

8. Bravo, P., C. Ticozzi and A. Cezza: The reaction of carbonyl-stabilized phosphonium and arsonium ylides with o-hydroxybenzaldehydes, Synthesis of o-hydroxy dalcones; Gazz. Chim. Ital. 105 (1975) 109-115.

9. Draffan, G. H., R. N. Stillwell and J. A. McCoskey: Electron impact-induced rearrangement of trimethylsilyl groups in long chain compounds; Organic Mass Spec. 1 (1968) 669-685.

10. Morita, $H$. J.: Identification of phenolic acids by gas chromatography-mass spectrometry; J. Chromatogr. 71 (1972) 149-153.

11. Horvat, R. J., and S. D. Senter: A GLC method for analysis of phenolic acids in plants; J. Agric. Food Chem. 28 (1980) 1292-1295.

\section{Authors' address:}

Tobacco and Health Laboratory, Agricultural Research,

U.S. Department of Agriculture,

P.O. Box 5677,

Athens, Georgia, 30613, U.S.A. 